\title{
Choroidal neovascularization in patient undergoing growth hormone treatment
}

\author{
João R de Oliveira Dias' \\ Eduardo B Rodrigues ${ }^{2}$ \\ Maurício Martinazzo² \\ Michel E Farah ${ }^{2}$ \\ 'Faculty of Medicine, University \\ of Passo Fundo, Rio Grande do Sul, \\ Brazil; ${ }^{2}$ Department of Ophthalmology, \\ Federal University of São Paulo \\ (UNIFESP), São Paulo, Brazil
}

\begin{abstract}
The association between growth-hormone (GH) and neovascular retinopathies in nondiabetic patients has been reported in earlier series. We report occurrence of choroidal neovascularization (CNV) in a 15-year-old male patient undergoing long-term GH therapy. The $\mathrm{CNV}$ could be a consequence of the GH-intake in a susceptible myopic patient.

Keywords: choroidal neovascularization, growth hormone, optical coherence tomography, retina, angiogenesis

The role of growth hormone $(\mathrm{GH})$ in human angiogenesis and retinal neovascularization has been demonstrated in recent years. ${ }^{1}$ The hormone is mitogenic for a variety of vascular cells and thereby may exert regulatory functions in controlling metabolism and differentiated endothelial cell expression. ${ }^{2,3}$ Herein we report occurrence of choroidal neovascularization (CNV) in a young patient undergoing long-term GH therapy.
\end{abstract}

\section{Case report}

A 15-year-old male patient presented with acute central vision loss OD. The patient had been taking daily dose of subcutaneous human GH (Eutropin ${ }^{\mathrm{TM}} 4 \mathrm{UI} /$ day) for the last 31 months due to early puberty and presumed diagnose of nanism. He had been also receiving monthly intramuscular doses of leuprolide $(3.75 \mathrm{mg})$ for 24 months. Past ocular history was positive for myopia and his past medical history was unremarkable. Family history was positive for nanism.

His best-corrected visual acuity (BCVA) was 20/30 OS; his BCVA OD dropped from $20 / 30$ to $20 / 100$ with metamorphopsia. The spherical correction was -10.75 diopter (D) OD and -9.75 D OS. Fundoscopy revealed myopic conus, peripapillary areas of retinal pigmented epithelium (RPE)-atrophy, but no detectable breaks in Bruch's membrane. Fluorescein angiography disclosed early hyperfluorescence with late leakage corresponding to CNV OD (Figure 1). Optical coherence tomography disclosed RPE and neurosensory retina elevation due to sub-RPE CNV. The CNV OD regressed after photodynamic therapy and vision improved to 20/30 without metamorphopsia.

\section{Comments}

Growth hormone intake is widely used in the treatment of disorders with GH deficiency such as nanism. We hypothesize that, in our patient, the CNV could be a consequence of the GH-intake in a susceptible myopic patient. High myopia can induce myopic degeneration as well as CNV, but usually in older patients mainly between 30 and 50 years of age. However, even if CNV induced by myopia is usually more seen in adults, it can also be found in teenagers. ${ }^{4}$ 


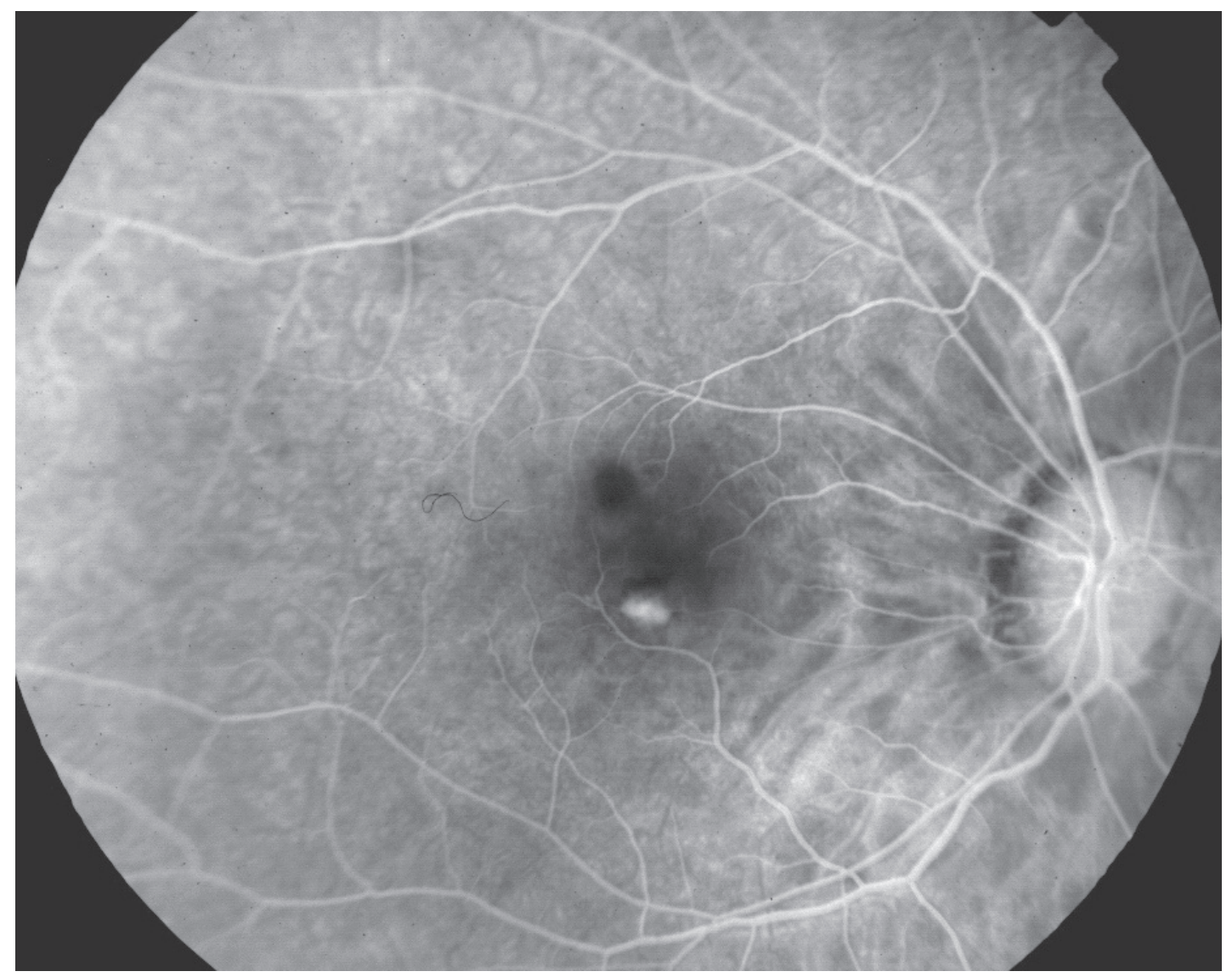

Figure I Fluorescein angiography demonstrated small inferior juxta-foveal choroidal neovascularization OD.

The association between $\mathrm{GH}$ and neovascular retinopathies in nondiabetic patients has been reported in earlier series. ${ }^{5}$ GH may promote stimulation of CNV through a variety of mechanisms, while one recent hypothesis involves tumor necrosis factor-mediated endothelial cells proliferation. ${ }^{6}$

Growth hormone-replacement therapy for patients with GH deficiency induces a diabetic-like retinopathy, which is attenuated after discontinuation of treatment. ${ }^{7}$ Moreover, Hellström and colleagues showed that diabetic children with congenital GH deficiency develop less retinal vascularization. ${ }^{8}$ Therefore, it is reasonable to speculate that GH level may have some relationship with CNV.

We describe occurrence of $\mathrm{CNV}$ in a young patient undergoing long-term GH therapy but, in this case, the role of GH in CNV formation is not definite because the effect of pathologic myopia can not be excluded. The link between iatrogenic CNV due to growth hormone intake remains unknown.

\section{Disclosure}

The authors report no conflicts of interest in this work.

\section{References}

1. Smith LEH, Kopchick JJ, Chen W, et al. Essential role of growth hormone in ischemia-induced retinal neovascularization. Science. 1997;276:1706-9.

2. Wright AD, Kohner EM, Oakley NW, et al. Serum growth hormone levels and the response of diabetic retinopathy to pituitary ablation. $\mathrm{Br}$ Med J. 1969;2:346-8.

3. Lincoln DT, Singal PK, Al-Banaw A. Growth hormone in vascular pathology: neovascularization and expression of receptors is associated with cellular proliferation. Anticancer Res. 2007;27:4201-18.

4. Bottoni F, Tilanus M. The natural history of juxtafoveal and subfoveal choroidal neovascularization in high myopia. Int Ophthalmol. 2001;24:249-55.

5. Koller EA, Green L, Gertner JM, et al. Retinal changes mimicking diabetic retinopathy in two nondiabetic, growth hormone-treated patients. J Clin Endocrinol Metab. 1998;83:2380-3.

6. Andiran N, Yordam N. TNF-alpha levels in children with growth hormone deficiency and the effect of long-term growth hormone replacement therapy. Growth Horm IGF Res. 2007;17:149-53.

7. Hansen R, Koller EA, Malozowski S. Full remission of growth hormone $(\mathrm{GH})$-induced retinopathy after $\mathrm{GH}$ treatment discontinuation: long-term follow-up. J Clin Endocrinol Metab. 2000;85:2627.

8. Hellström A, Svensson E, Carlsson B, et al. Reduced retinal vascularization in children with growth hormone deficiency. J Clin Endocrinol Metab. 1999;84:795-8. 